\title{
Multiple Response Optimization of machining parameters on turning of AA 6063 T6 aluminum alloy which established on Taguchi L9 orthogonal array coupled with Grey relational analysis.
}

\section{S. Sai Ravi Kiran'1, Sanapala Sri Ram², Tangeti Bhaskararao², Boddu Eswar Venkat Sai², Kari Suraj Kumar²,} Duvvi Veera Venkata Pavan Kumar ${ }^{2}$

${ }^{1}$ Assistant Professor, Department of Mechanical Engineering, Anil Neerukonda Institute of Technology \& Sciences, Visakhapatnam, Andhra Pradesh, India

2B Tech. , Department of Mechanical Engineering, Anil Neerukonda Institute of Technology \& Sciences, Visakhapatnam, Andhra Pradesh, India

\section{ABSTRACT}

Article Info

Volume 8, Issue 3

Page Number : 974-982

Publication Issue

May-June-2021

Article History

Accepted : 18 June 2021

Published : 27 June 2021
With numerous responses established on Taguchi L9, orthogonal array coupled with current work proposes a novel methodology for optimizing machining parameters on turning of AA 6063 T6 aluminum alloy. Experimental assessments are accomplished on AA 6063 T6 aluminum alloy. Turning trails are carried out under dry cutting conditions using an uncoated carbide insert. Cutting parameters such as cutting speed, feed rate, and depth of cut are optimized in this effort while numerous responses such as surface roughness $(\mathrm{Ra})$ and material removal rate are taken into consideration (MRR). From the grey analysis, a grey relational grade(GRG) is calculated. The optimal amounts of parameters have been identified based on the values of grey relational grade, and then ANOVA is used to determine the significant influence of parameters. To authenticate the test result, a confirmation test is executed. The result of the experiments shows that by using this method. the turning process responses can be significantly improved.

Keywords : Material Removal Rate, ANOVA, Taguchi Method, Grey Relation Analysis, $\mathrm{S} / \mathrm{N}$ ratio

\section{INTRODUCTION}

It has always become difficult for Manufacturing Industries to produce products conveniently with high quality and higher production rates to remain in the competitive world. The desired shape, size of the product can be achieved by the process called turning, which is performed by rotating parts that rotate the workpiece and the cutting tools which cut the unwanted material to get our desired shape which is done by using Lathe machines. Turning is important and widely used in engineering industries. Surface roughness, often known as roughness, is a characteristic of surface texture. The deviations in the

Copyright: (C) the author(s), publisher and licensee Technoscience Academy. This is an open-access article distributed under the terms of the Creative Commons Attribution Non-Commercial License, which permits unrestricted non-commercial use, distribution, and reproduction in any medium, provided the original work is properly cited 
direction of a real surface's normal vector from its ideal form are used to quantify it. The surface is rough if these variances are considered, the surface is smooth if they are minimal roughness is often thought of as the high frequency, short wavelength component of a measured surface in the surface metrology. At the same time, industries need a higher material removal rate(MRR) so that they can raise the production rate while maintaining high quality. Increases in process parameters such as cutting speed, feed, and depth of cut might result in all high MRR. High cutting speeds require more power, which may be greater than the machine tool's capacity. At the same time, as the process parameters are increased, the cutting temperature rises. Therefore selecting the appropriate process parameters plays a vital role in the effectiveness, efficiency, and overall economy of manufacturing by machining industries to achieve these objectives (higher MRR and product quality). In turning, parameters like cutting speed, feed rate, and depth of cut affect surface finish, roundness and MRR. Choudhury and Bartarya [5] focused on the design of experiments and the neural network for the prediction of tool wear. The input parameters were cutting speed, feed, and depth of cut; flank wear, surface finish, and cutting zone temperature were selected as outputs. Taguchi method is applied for finding out the optimal value of surface roughness under the optimum cutting condition in turning SCM 440 alloy steel The experiment was designed by using the Taguchi method and experiments were conducted and results thereof were analyzed with the help of the ANOVA (Analysis of Variance) method[13]. The orthogonal array of Taguchi method coupled with grey

relational analysis considering three parameters viz. speed, cutting depth, feed rate for optimizing two responses: surface roughness, and material removal rate in precision turning. The MINITAB software was explored to analyze the mean effect of the Signal-toNoise $(\mathrm{S} / \mathrm{N})$ ratio to achieve the multi-objective features [16]. A gray relational grade is determined to evaluate the multiple responses. In the present study, experimental details using the Taguchi method of parameter design have been employed for optimizing multiple performance characteristics such as surface roughness, roundness, and MRR for turning AA 6063 T6. Further, for the optimization of multiple response characteristics, grey relational analysis was used.

\section{MATERIAL SPECIFICATION}

AA 6063 T6 has a composition of 0.6 wt.\% Si, 0.34 wt.\% Fe, 0.09 wt.\% Cu, 0.09 wt. \% Mn, 0.88 wt.\% Mg, 0.092 wt.\% Cr, 0.095 wt.\% Zn, 0.092 wt.\% Ti, 97.721 wt.\% Al.

This metal is commonly used to make doors, extrusion, window frames, and irrigation tubing. CNC lathe was used for machining. The tool used is an uncoated carbide insert tool.

The specification of the cutting tool is DCGT $11 \mathrm{~T} 3$ 04. The surface roughness was measured using the Surfcorder SE 1200, Surface profilometer. The machining was done under dry-cutting conditions.

\section{EXPERIMENTAL WORK}

The trails with three parameters and three levels were designed using Taguchi's L9 orthogonal array. Experiments were conducted based on Taguchi's method which is a powerful tool used in the design of experiments. Taguchi advocates the use of orthogonal array designs to assign the factors chosen for the experiment. The advantage of the Taguchi method is that it uses a special design of orthogonal arrays to study the entire parameter space with only a small number of experiments. Compared to the conventional approach of experimentation, this method reduces drastically the number of experiments that are required to model the response functions.Table(1) shows the levels assigned to the factors as well as the various parameters used. The experimental results for the L9 orthogonal array are given in Table(2). 


\section{RESULTS AND DISCUSSION}

\section{A. Multi-Response Optimization Using GRA}

Taguchi's technique is sufficient for determining the best process parameter settings for a single response characteristic. Multi-response optimization using GRA is the preferred strategy when there are two or more responses with dissimilar quality attributes. Grey analysis can also be utilized to determine the similarity between seemingly irregular finite data. As a result, the following GRA procedures are used to achieve multi-response optimization of wear parameters in this work.

\section{B. Grey Relational Generation}

The role of the factors is ignored in GRA when the standard value and reference sequence range are both quite large.GRA may also produce erroneous results if the goals and directions of the factors are incompatible. As a result, data pre-processing is carried out to normalize the original reference sequences to a comparable sequence in the range of zero to one. This method of pre-processing data into a group of sequences is known ass grey relational generation. When using GRA to preprocess data, the response of the transformed sequence can be divided into two quality characteristics, namely larger-the-better or smaller-the-better. For smaller-the-better characteristic, the sequence can be normalized using Equation (1):

$$
x_{i}^{*}(k)=\frac{\operatorname{maxy}_{i}(k)-y_{i}(k)}{\max _{i}(k)-\min y_{i}(k)}
$$

Where $x_{i}^{*}(\mathrm{k})$ denotes the reference sequence after pre-processing for the $i$ th experiment and $y_{i}(\mathrm{k})$ represents the initial sequence of the mean of the responses.

\section{Computation of Grey Relational Coefficient and Grade}

Once the sequence is normalized, the next step is to calculate the deviation sequence of the reference sequence using Equation (2):

$$
\Delta_{0 i}(k)=\left|x_{0}^{*}(k)-x_{i}^{*}(k)\right|
$$

where $\Delta_{0 i}(\mathrm{k}), x_{0}^{*}(\mathrm{k})$ and $x_{i}^{*}(\mathrm{k})$ refer to the deviation, reference, and comparability sequences, respectively. The grey relational coefficient (GRC) is then determined using Equation (3):

$$
\xi_{i}(k)=\frac{\Delta_{\min }+\zeta \Delta_{\max }}{\Delta_{0 i}(k)+\zeta \Delta_{\max }}
$$

where, $\xi_{i}(k)$ signifies the GRC of individual response variables computed as a function of $\Delta_{\min }$ and $\Delta_{\max }$, the minimum and maximum deviations of each response variable. The distinguishing or identification coefficient represented by $\zeta$, defined in the range $\zeta \in[0,2.5]$, is generally set at 0.5 to allocate equal weights to every parameter. As shown in Equation (4), a composite grey relational grade (GRG), is then computed by averaging the GRC of each response variable:

$$
\gamma_{i}=\frac{1}{n} \sum_{i=1}^{n} \xi_{i}(k)
$$

where $\gamma_{i}$ represents the value of GRG determined for the ith experiment, $n$ being the aggregate count of performance characteristics. Once the optimal level of the factors is determined using GRG, the final step is to predict and verify the quality characteristics using Equation (5):

$$
\gamma_{\text {predicted }}=\gamma_{m}+\sum_{i=1}^{q} \gamma_{0}-\gamma_{m}
$$

Where $\gamma_{0}$ denotes the maximum of average GRG at the optimal level of factors and $\gamma_{m}$ represents the mean GRG. The quantity $q$ indicates the number of factors affecting the response value.

An order of 1 is allotted to the greatest grey relational grade. Grey relational grades are calculated using Eq. (4) and grey relational order was figured out in the 
table(3). From table(2), we come to know that the control parameter's setting of 2(experiment 2) had the greatest grey relational grade and this indicates that experiment 2 was the optimal turning factor setting for minimum surface roughness and MRR simultaneously among the chosen nine experiments. The larger better $\mathrm{S} / \mathrm{N}$ quality characteristics were considered for the grey relational grade since higher multiple performance characteristics are our target. The ideal level of a parameter is the one with an $\mathrm{S} / \mathrm{N}$ ratio. So the optimal process parameter setting for the multiple performance characteristics was N1f2d2.

\section{S/N Ratios in the Taguchi Method}

To reduce variance and optimize process parameters, the Taguchi method uses orthogonal arrays. The signal-to-noise $(\mathrm{S} / \mathrm{N})$ ratio is used as a performance characteristic in the Taguchi method to assess process robustness and deviation from desired values. The $\mathrm{S} / \mathrm{N}$ ratio is a logarithmic function that is calculated by dividing the signal (mean) by the noise (standard deviation). To diminish noise and the effects of uncontrollable factors, higher values of $\mathrm{S} / \mathrm{N}$ ratios are preferred. High $\mathrm{S} / \mathrm{N}$ ratios indicate the improved quality of the product. There exist three types of $\mathrm{S} / \mathrm{N}$ ratios, namely, higher-the-better, nominal-the-best, and smaller-the-better as shown in Equations (6)-(8):

$\left(\frac{S}{N}\right)_{H T B}=-10 * \log _{10}\left(\frac{1}{n} \sum_{i=1}^{n} \frac{1}{y_{i}^{2}}\right)$

$\left(\frac{S}{N}\right)_{N T B}=-10 * \log _{10}\left(\frac{1}{n} \sum_{i=1}^{n} y_{i}^{2}\right)$

$\left(\frac{S}{N}\right)_{S T B}=-10 * \log _{10}\left(\frac{1}{n} \sum_{i=1}^{n} y_{i}^{2}\right)$

where $\mathrm{n}$ is the number of experiments, $y_{i}$ represents the response value of the $i$ th experiment in the OA, $\overline{y^{2}}$ indicates the mean, and $s^{2}$ the variance of the observed data.

\section{E. Analysis of Variance(ANOVA)}

ANOVA is conventionally used to investigate whether the experimental design parameters have a significant effect on the responses. The ANOVA table is also commonly used to examine the interactions between variables. In general, the F-test is used to assess the extent to which factors influence test results.

This table provides the order of most influencing factor in determining the multiple performance characteristics or Grey relational Grade.

The Depth of cut is the 1st influencing factor which has the highest mean of GRG at Level-2. So the depth of cut has Rank 1 in the table.

The Spindle speed is the 2nd most influencing factor which has the highest mean of GRG at Level-1. So the spindle speed has Rank 2 in the table.

The Feed rate is the 3rd most influencing factor which has the highest mean of GRG at Level-2. So the feed rate has Rank 3 in the table.

The main effects plot for the mean for GRG is shown in Fig 1.

The main effects plot for GRG for Data Means was created in Minitab for each value of a categorical variable. Each variable's points are connected by a line. Look at the line to determine whether the main effect is present for a categorical variable.

The Response Table for Signal-to-Noise Ratios contains a row for the average signal-to-noise ratio for each factor level, Delta, and Rank. Each factor has its column in the table.

Each factor level. Delta and Rank have a row in the Response Table for Standard Deviations that contains the average signal-to-noise ratio. Each factor has its column in the table.

Delta is the difference between the maximum and minimum average response (signal-to-noise ratio or standard deviation) for the factor.

The Rank is the rank of each Delta, where Rank 1 is the largest Delta.

The larger, better $\mathrm{S} / \mathrm{N}$ quality characteristics were considered for the grey relational grade since higher multiple performance characteristics are our target. The optimal level is the level of a parameter with the highest $\mathrm{S} / \mathrm{N}$ ratio. 
The main effects plot for the $\mathrm{S} / \mathrm{N}$ ratio for $\mathrm{GRG}$ is shown in Fig 2.

In these results, the main effects plot for the $\mathrm{S} / \mathrm{N}$ ratio indicates that Depth of Cut has the largest effect on the signal-to-noise ratio. On average, experimental runs with the depth of cut at level 2 had much higher signal-to-noise ratios than experimental runs with the depth of cut at levels $1 \& 3$. Feed Rate had a small effect or no effect on the signal-to-noise ratio.

\section{F. Estimated coefficients using uncoded units}

Minitab displays the coefficients in uncoded units in addition to coded units if the two units differ. For each term in the model, there is a coefficient. These coefficients are useful to construct an equation representing the relationship between the response and the factors.

Thus, the finest combination values for maximizing the multiple performance characteristics or grey relational grade (GRG) were spindle speed of 2000 $\mathrm{rpm}$, feed rate of $0.05 \mathrm{~mm} / \mathrm{rev}$, and depth of cut of $0.15 \mathrm{~mm}$. The response table for the means of grey relational grade is shown in Table (4). The response table for the $\mathrm{S} / \mathrm{N}$ ratios of grey relational grade is shown in Table (5).ANOVA output of the multiple performance characteristics is given in Table (6). From the analysis of this table, it could be concluded that depth of cut, spindle speed followed by feed rate, and, are significantly affecting the grey relational grade.

\section{G. Graphs}

\section{1) Normal Probability Plot}

A graph is plotted between the residuals versus their expected values when the distribution is normal. The analysis residuals should be regularly distributed. In practice, for balanced or nearly balanced designs or data with a large number of observations, moderate departures from normality do not seriously affect the results. The normal probability plot of the residuals should roughly follow a straight line. Shown in Fig 3.

\section{2) Residuals versus fits}

A graph is plotted between the residuals versus the fitted values. The residuals should be scattered randomly about zero. Shown in Fig 4.

\section{H. Results of Confirmation Experiment for GRG :}

The purpose of this confirmation experiment is to verify the improvement in the quality characteristics. After determining the optimal level, the following equation can be used to forecast the best response:

$$
\gamma_{\text {predicted }}=\gamma_{m}+\sum_{i=1}^{q} \gamma_{0}-\gamma_{m}
$$

where $\gamma_{m}$ is the total mean $\mathrm{S} / \mathrm{N}$ ratio, $\gamma_{0}$ is the mean $\mathrm{S} / \mathrm{N}$ ratio at an optimal level, $\mathrm{n}$ is the number of main design parameters that affect the quality characteristics.

Based on Eq (9) the grey relational grade (GRG) is predicted for the optimal combination of parameters (N1-f2-d2) and its value is 0.7184. Lastly, a confirmation test was conducted using the optimum combination of parameters (N1-f2-d2). Table (7). shows the comparison of predicted multiple performance characteristics (GRG) with the actual one. The grey relational grade for the confirmation experiment is found to be 0.7640 .

The results of the confirmation experiment have been done for a different level of cutting parameters which are Initial and Optimal Cutting parameters. The initial cutting parameters are taken as N1f1d1 which is the 1st experiment condition and Optimal cutting parameters are taken as $\mathrm{N} 1 \mathrm{f} 2 \mathrm{~d} 2$ which is the optimal process parameter setting for the multiple performance characteristics. The Prediction value of GRG and S/N ratio are 0.7184 and -2.76601 respectively with the lower spindle speed of 2000 $\mathrm{rpm}$, lower feed rate of $0.05 \mathrm{~mm} / \mathrm{rev}$, and medium depth of cut of $0.15 \mathrm{~mm}$ with the estimated multiple performance characteristics (GRG). The Experimental value of GRG and $\mathrm{S} / \mathrm{N}$ ratio are 0.7640 and -2.4271 respectively of parameter setting N1f2d2. The percentage of error between the predicted and experimental values of the multiple performance 
characteristics during the confirmation experiments is almost within $5.96 \%$. So, we can say the improvement in quality characteristics has been verified by a confirmation experiment. The improvement in the $\mathrm{S} / \mathrm{N}$ ratio from the initial cutting parameters to the optimal cutting parameters is calculated by the difference of them,i.e., 5.229 $2.4271=2.8019 \mathrm{~dB}$ for $\mathrm{GRG}$

\section{Figures and Tables:}

TABLE I. MACHINING PARAMETERS

\begin{tabular}{|c|c|c|c|c|c|}
\hline \multicolumn{7}{|c|}{ Machining Parameters } \\
\hline Sno & Factors & Symbol & $\begin{array}{c}\text { Level } \\
\mathbf{1}\end{array}$ & $\begin{array}{c}\text { Level } \\
\mathbf{2}\end{array}$ & $\begin{array}{c}\text { Level } \\
\mathbf{3}\end{array}$ \\
\hline & $\begin{array}{c}\text { Spindle } \\
\text { Speed } \\
\text { (rpm) }\end{array}$ & $\mathrm{N}$ & 2000 & 3500 & 5000 \\
\hline 2 & $\begin{array}{c}\text { Feed Rate } \\
\text { (mm/rev) }\end{array}$ & $\mathrm{F}$ & 0.05 & 0.075 & 0.1 \\
\hline 3 & $\begin{array}{c}\text { Depth of } \\
\text { Cut (mm) }\end{array}$ & D & 0.1 & 0.15 & 0.2 \\
\hline
\end{tabular}

TABLE II. DESIGN OF EXPERIMENTS

\begin{tabular}{|c|c|c|c|c|c|}
\hline \multicolumn{7}{|c|}{ Design of Experiments } \\
\hline Sno & N & F & d & Ra & MRR \\
\hline 1 & 2000 & 0.05 & 0.1 & 0.380 & 0.2123 \\
\hline 2 & 2000 & 0.075 & 0.15 & 0.360 & 0.4302 \\
\hline 3 & 2000 & 0.1 & 0.2 & 0.535 & 0.6872 \\
\hline 4 & 3500 & 0.05 & 0.15 & 0.388 & 0.3865 \\
\hline 5 & 3500 & 0.075 & 0.2 & 0.509 & 0.6872 \\
\hline 6 & 3500 & 0.1 & 0.1 & 0.533 & 0.5208 \\
\hline 7 & 5000 & 0.05 & 0.2 & 0.459 & 0.5821 \\
\hline 8 & 5000 & 0.075 & 0.1 & 0.469 & 0.4899 \\
\hline 9 & 5000 & 0.1 & 0.15 & 0.556 & 0.8531 \\
\hline
\end{tabular}

TABLE III.

\begin{tabular}{|c|c|c|c|c|c|c|c|c|}
\hline \multirow{2}{*}{$\begin{array}{l}\text { Exp. } \\
\text { No. }\end{array}$} & \multicolumn{2}{|c|}{ Normalization } & \multicolumn{2}{|c|}{$\begin{array}{l}\text { Deviation } \\
\text { Sequence }\end{array}$} & \multicolumn{2}{|c|}{$\begin{array}{l}\text { Grey Relational } \\
\text { Coefficient -GRC }\end{array}$} & \multirow{2}{*}{$\begin{array}{c}\text { Grey } \\
\text { Relational } \\
\text { Grade - } \\
\text { GRG }\end{array}$} & \multirow{2}{*}{$\begin{array}{l}\text { Rank } \\
\text { Order }\end{array}$} \\
\hline & $\mathbf{R a}$ & MRR & $\mathbf{R a}$ & MRR & $\mathbf{R a}$ & MRR & & \\
\hline 1 & 0.89796 & 0.00000 & 0.10204 & 1.00000 & 0.83051 & 0.33333 & 0.58192 & 4 \\
\hline 2 & 1.00000 & 0.34004 & 0.00000 & 0.65996 & 1.00000 & 0.43105 & 0.71553 & 1 \\
\hline 3 & 0.10714 & 0.74110 & 0.89286 & 0.25890 & 0.35897 & 0.65885 & 0.50891 & 7 \\
\hline 4 & 0.85714 & 0.27185 & 0.14286 & 0.72815 & 0.77778 & 0.40712 & 0.59245 & 3 \\
\hline 5 & 0.23980 & 0.74110 & 0.76020 & 0.25890 & 0.39676 & 0.65885 & 0.52781 & 5 \\
\hline 6 & 0.11735 & 0.48143 & 0.88265 & 0.51857 & 0.36162 & 0.49088 & 0.42625 & 9 \\
\hline 7 & 0.49490 & 0.57709 & 0.50510 & 0.42291 & 0.49746 & 0.54177 & 0.51961 & 6 \\
\hline 8 & 0.44388 & 0.43321 & 0.55612 & 0.56679 & 0.47343 & 0.46870 & 0.47106 & 8 \\
\hline 9 & 0.00000 & 1.00000 & 1.00000 & 0.00000 & 0.33333 & 1.00000 & 0.66667 & 2 \\
\hline
\end{tabular}

TABLE IV. RESPONSE TABLE FOR MEANS

\begin{tabular}{|c|c|c|c|}
\hline & Initial Cutting Parameters & \multicolumn{2}{|c|}{ Optimal Cutting Parameters } \\
\cline { 3 - 4 } Level & \multirow{2}{*}{ N1 f1 d1 } & \multicolumn{2}{|c|}{ N1 f2 d2 } \\
\cline { 3 - 4 } & & Prediction & Experiment \\
\hline GRG & 0.5819 & 0.7184 & 0.7640 \\
\hline S/N Ratio & -5.229 & -2.76601 & -2.4271 \\
\hline
\end{tabular}

Average mean $=0.55669$

TABLE V. RESPONSE TABLE FOR S/N RATIOS Larger is better

\begin{tabular}{|c|c|c|c|}
\hline Level & $\mathbf{N}$ & $\mathbf{F}$ & $\mathbf{D}$ \\
\hline 1 & 0.6021 & 0.5647 & 0.4931 \\
\hline 2 & 0.5155 & 0.5715 & 0.6582 \\
\hline 3 & 0.5524 & 0.5339 & 0.5188 \\
\hline Delta & 0.0866 & 0.0375 & 0.1651 \\
\hline Rank & 2 & 3 & 1 \\
\hline
\end{tabular}

TABLE VI

\begin{tabular}{|c|c|c|c|}
\hline Level & $\mathbf{N}$ & $\mathbf{F}$ & $\mathbf{D}$ \\
\hline 1 & -4.492 & -4.979 & -6.216 \\
\hline 2 & -5.835 & -4.999 & -3.659 \\
\hline 3 & -5.249 & -5.599 & -5.701 \\
\hline Delta & 1.342 & 0.620 & 2.557 \\
\hline Rank & 2 & 3 & 1 \\
\hline
\end{tabular}

TABLE VII

\begin{tabular}{|c|c|c|c|c|c|c|}
\hline $\begin{array}{c}\text { Sour } \\
\text { ce }\end{array}$ & $\begin{array}{c}\text { D } \\
\text { F }\end{array}$ & Adj SS & $\begin{array}{c}\text { Adj } \\
\text { MS }\end{array}$ & $\begin{array}{c}\text { F- } \\
\text { Value }\end{array}$ & $\begin{array}{c}\text { P- } \\
\text { Value }\end{array}$ & $\begin{array}{c}\text { Percentage } \\
\text { Contributio } \\
\text { n(\%) }\end{array}$ \\
\hline $\mathrm{N}$ & 2 & $\begin{array}{c}0.0113 \\
35\end{array}$ & $\begin{array}{c}0.0056 \\
67\end{array}$ & 1.63 & 0.0381 & 16.65 \\
\hline $\mathrm{F}$ & 2 & $\begin{array}{c}0.0023 \\
98\end{array}$ & $\begin{array}{c}0.0011 \\
99\end{array}$ & 0.34 & 0.0744 & 3.52 \\
\hline $\mathrm{D}$ & 2 & $\begin{array}{c}0.0473 \\
72\end{array}$ & $\begin{array}{c}0.0236 \\
86\end{array}$ & 6.79 & 0.0128 & 69.58 \\
\hline Error & 2 & $\begin{array}{c}0.0069 \\
72\end{array}$ & $\begin{array}{c}0.0034 \\
86\end{array}$ & & & \\
\hline Total & 8 & $\begin{array}{c}0.0680 \\
76\end{array}$ & & & & \\
\hline
\end{tabular}




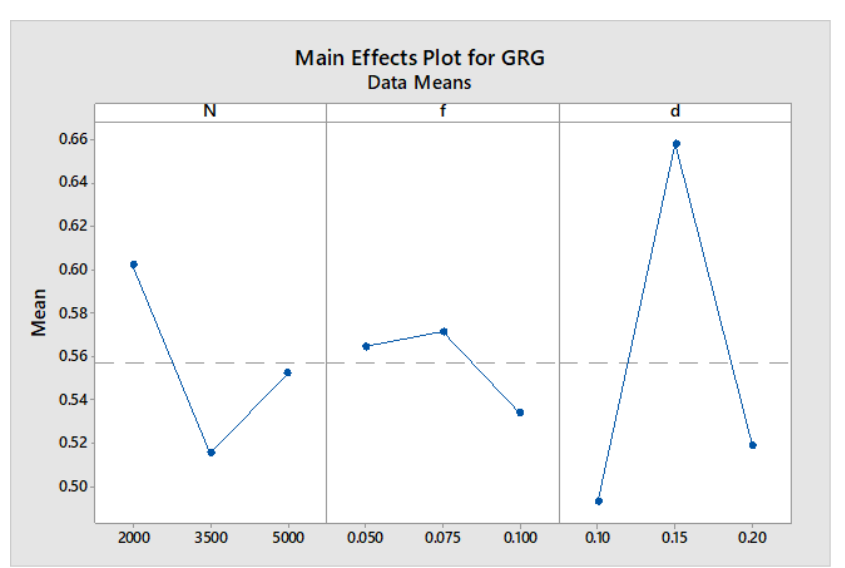

Fig 1: Mean Effect plot for GRG

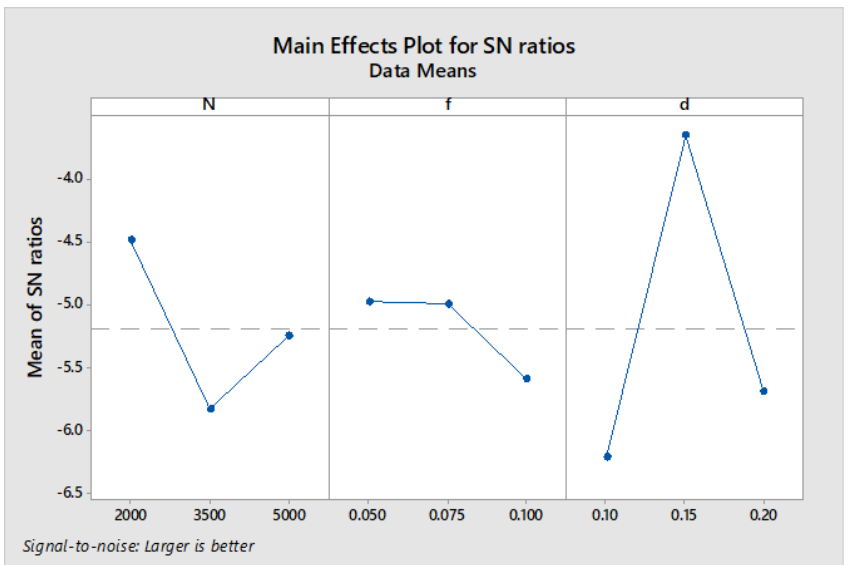

Fig 2: Main Effect Plot for SN ratio



Fig 3:Normal Probability Plot

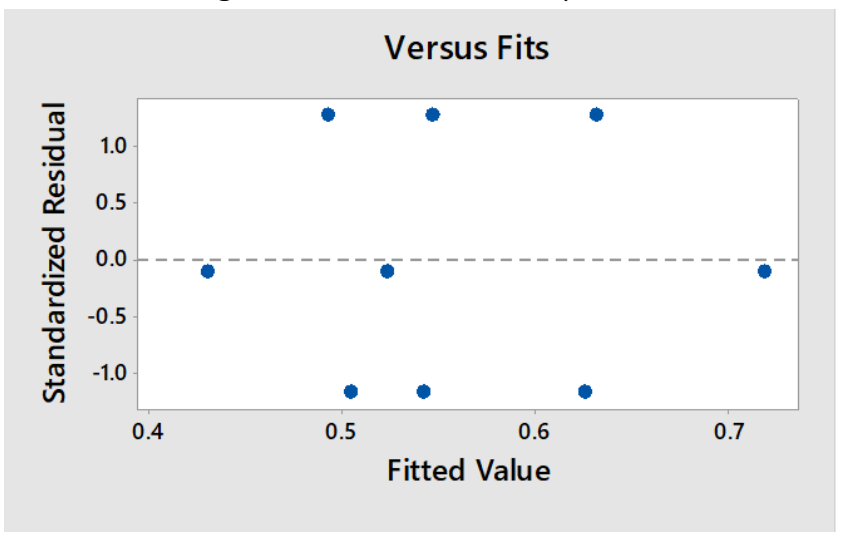

Fig 4: Versus Fits

\section{v. CONCLUSION}

The surface roughness $(\mathrm{Ra})$ and material removal rate (MRR) were measured under different cutting conditions for diverse combinations of machining parameters. The conclusions arrived, at the end of this work are as follows:

1. From this analysis, it is revealed that depth of cut and spindle speeds are prominent factors that affect the turning of aluminum alloy. The depth of cut $(\mathrm{p}=69.58 \%)$ is the most influencing factor in determining the multiple performance characteristics or grey relational grade (GRG) followed by spindle speed $(\mathrm{p}=16.65 \%)$ and feed rate $(\mathrm{p}=3.52 \%)$.

2. The best multiple performance characteristics were obtained with an uncoated carbide insert when turning aluminum alloy with the lower spindle speed of $2000 \mathrm{rpm}$, lower feed rate of $0.05 \mathrm{~mm} / \mathrm{rev}$, and medium depth of cut of 0.15 $\mathrm{mm}$ with the estimated multiple performance characteristics (GRG) of 0.7184. The experimental value of GRG for this combination of parameters is 0.7640 .

3. The percentage of error between the predicted and experimental values of the multiple performance characteristics during the confirmation experiments is almost within $5.96 \%$.

4. The improvement in the $\mathrm{S} / \mathrm{N}$ ratio from the initial cutting parameters to the optimal cutting parameters is $2.8019 \mathrm{~dB}$ for GRG.

5. The value of multiple performance characteristics obtained from the confirmation experiment is within the $95 \%$ confidence interval of the predicted optimum condition. 


\section{REFERENCES}

[1]. Zhou Q., Hong G. S., and Rahman M., “A New Tool Life Criterion For Tool Condition Monitoring Using a Neural Network", Engineering Application Artificial Intelligence, Volume 8, Number 5, pp. 579-588.

[2]. Lin W. S., Lee B. Y., Wu C. L., (2001), "Modelling the surface roughness and cutting force for turning", Journal of Materials Processing Technology, Volume 108, pp. 286293.

[3]. Suresh P. V. S., Rao P. V., and Deshmukh S. G., (2002), "A genetic algorithmic approach for optimization of surface roughness prediction model", International Journal of Machine Tools and Manufacture, Volume 42, pp. 675-680.

[4]. Lee S. S. and Chen J. C., (2003), "Online surface roughness recognition system using artificial neural networks system in turning operations" International Journal of Advanced Manufacturing Technology, Volume 22, pp. 498-509.

[5]. Choudhury S. K. and Bartarya G., (2003), "Role of temperature and surface finish in predicting tool wear using neural network and design of experiments", International Journal of Machine Tools and Manufacture, Volume 43, pp. 747753.

[6]. Chien W.-T. and Tsai C.-S., (2003), "The investigation on the prediction of tool wear and the determination of optimum cutting conditions in machining 17-4PH stainless steel”, Journal of Materials Processing Technology, Volume 140, pp. 340-345.

[7]. Özel T. and Karpat Y., (2005), "Predictive modeling of surface roughness and tool wear in hard turning using regression and neural networks", International Journal of Machine Tools and Manufacture, Volume 45, pp. 467479.
[8]. Kohli A. and Dixit U. S., (2005)," A neuralnetwork-based methodology for the prediction of surface roughness in a turning process", International Journal of Advanced Manufacturing Technology, Volume 25, pp.118-129.

[9]. Ahmed S. G., (2006), "Development of a Prediction Model for Surface Roughness in Finish Turning of Aluminum", Sudan Engineering Society Journal, Volume 52, Number 45, pp. 1-5. 3.

[10]. Abburi N. R. and Dixit U. S., (2006), “A knowledge-based system for the prediction of surface roughness in turning process" Robotics and ComputerIntegrated Manufacturing, Volume 22, pp. 363-372.

[11]. Zhong Z. W., Khoo L. P., and Han S. T., (2006), "Prediction of surface roughness of turned surfaces using neural networks", International Journal of Advanced Manufacturing Technology, Volume 28, pp. 688-693.

[12]. Kumanan S., Saheb S. K. N., and Jesuthanam C. P., (2006), "Prediction of Machining Forces using Neural Networks Trained by a Genetic Algorithm", Institution of Engineers (India) Journal, Volume 87, pp. 11-15.

[13]. Thamizhmanii S., Saparudin S., and Hasan S., (2007), "Analysis of Surface Roughness by Using Taguchi Method", Achievements in Materials and Manufacturing Engineering, Volume 20, Issue 1-2, pp. 503-505.

[14]. Natarajan U., Arun P., Periasamy V. M., (2007), "On-line Tool Wear Monitoring in Turning by Hidden Markov Model (HMM)" Institution of Engineers (India) Journal (PR), Volume 87, pp. 31-35.

[15]. Özel T., Karpat Y., Figueira L., and Davim J. P., (2007), "Modeling of surface finish and tool flank wear in turning of AISI D2 steel with ceramic wiper inserts", Journal of Materials Processing Technology, Volume189, pp.192198. 
[16]. Wang M. Y. and Lan T. S., (2008), "Parametric Optimization on Multi-Objective Precision Turning Using Grey Relational Analysis". Information Technology Journal, Volume 7, pp.1072-1076.

[17]. Sahoo P., Barman T. K., and Routara B. C., (2008), "Taguchi based practical dimension modeling and optimization in CNC turning", Advance in Production Engineering and Management, Volume 3, Number 4, pp. 205217.

[18]. Reddy B. S., Padmanabhan G., and Reddy K. V. K., (2008), "Surface Roughness Prediction Techniques for CNC turning", Asian Journal of Scientific Research, Volume 1, Number 3, pp. 256-264.

[19]. Wannas A. A., (2008), "RBFNN Model for Prediction Recognition of Tool Wear in Hard Turning", Journal of Engineering and Applies Science, Volume 3, Number 10, pp. 780-785.

[20]. Fu P. and Hope A. D., (2008), “A Hybrid Pattern Recognition Architecture for Cutting Tool Condition Monitoring" Technology and
Applications, Volume 24, Number 4, pp. 548558.

[21]. Shetty R., Pai R., Kamath V., and Rao S. S., (2008), "Study on Surface Roughness Minimization in Turning of DRACs using Surface Roughness Methodology and Taguchi under Pressured Steam Jet Approach", ARPN Journal of Engineering and Applied Sciences, Volume 3, Number 1, pp. 59-67.

\section{Cite this article as :}

D. S. Sai Ravi Kiran, Sanapala Sri Ram, Tangeti Bhaskararao, Boddu Eswar Venkat Sai, Kari Suraj Kumar, Duvvi Veera Venkata Pavan Kumar, "Multiple Response Optimization of machining parameters on turning of AA 6063 T6 aluminum alloy which established on Taguchi L9 orthogonal array coupled with Grey relational analysis", International Journal of Scientific Research in Science and Technology (IJSRST), Online ISSN : 2395-602X, Print ISSN : 2395-6011, Volume 8 Issue 3, pp. 974-982, May-June 2021. Available at doi : https://doi.org/10.32628/IJSRST2183205 Journal URL : https://ijsrst.com/IJSRST2183205 